Prejudice-Relevant Correlates of Attitudes Towards Refugees: A Meta-Analysis

\author{
Misha Mei Cowling ${ }^{1}$ \\ Joel R. Anderson ${ }^{1,3}$ \\ Ferguson, Rose ${ }^{1,2}$
}

${ }^{1}$ Faculty of Health Sciences, Australian Catholic University, Australia.

${ }^{1}$ Faculy of Health, Federation University, Australia.

${ }^{3}$ Correspondance:

School of School of Behavioural and Health Sciences, Australian Catholic University, Melbourne Campus (St Patrick), Locked Bag 4115, Victoria 3065, Australia; Tel: +61 (0)3 9953 3112; Fax: +61 (0)3 9953 3205; email: joel.anderson@acu.edu.au

This research was supported by a grant from the School of Psychology at Australian Catholic University.

Word count: 7,517 (4,997 words excluding references; abstract of 173 words).

Accepted for publication at the Journal of Refugee Studies

Please cite as: Cowling, M., Anderson, J R., \& Ferguson, R. (in press). Prejudice-Relevant

Correlates of Attitudes Towards Refugees: A Meta-Analysis. Doi: 10.1093/jrs/fey062 


\begin{abstract}
This paper meta-analyses the available data on attitudes towards refugees and asylum seekers, with the aim of estimating effect sizes for the relationships between these attitudes and prejudice-relevant correlates. Seventy studies $\left(N_{\text {total }}=13,720\right)$ were located using systematic database searches and calls for unpublished data. In the case of demographic factors, being male, religious, nationally identified, politically conservative, and less educated were associated with negative attitudes (Fisher's $z \mathrm{~s}=0.11,0.17,0.18,0.21$, \& -0.16 , respectively). For ideological factors, increases in right-wing authoritarianism and socialdominance orientations correlated with negative attitudes, while the endorsement of macro (but not micro) justice principles were associated with positive attitudes (Fisher's $z \mathrm{~s}=0.50$, $0.50,-0.29, \& 0.00$ respectively). Perceptions of refugees as symbolic and realistic threats were the strongest correlates of negative attitudes (Fisher's $z \mathrm{~s}=0.98, \& 1.11$, respectively). These findings have contributed to the growing body of knowledge that endeavors to understand the antecedents of refugee-specific prejudice, and are discussed in light of the global refugee crisis.
\end{abstract}


Prejudice-Relevant Correlates of Attitudes Towards Refugees: A Meta-Analysis

'On average, 20 people were driven from their homes every minute last year, or one every three seconds - less than the time it takes to read this sentence.'

$\sim$ UNHCR, 2017

\section{The Refugee Crisis}

The United Nations High Commission for Refugees has documented record-high levels of forced global displacement - at the end of 2016 there were 65.6 million individuals that had been forcibly displaced as a result of ongoing war, conflict, and persecution (UNHCR, 2017). Of these, around 22.5 million were externally displaced refugees and 2.8 million were asylum seekers. Under international law, refugees are recognized as being persons fleeing from conflicts, persecution, and man-made or natural disasters, in which the denial of sanctuary would result in fatal consequences, and as such are legally granted asylum in a country that is not their own (UNHCR, 2016). An asylum seeker is an individual fleeing from conflict and persecution, but whose application for refugee status is still being processed. In this paper, the term "refugee" will be used over-inclusively to refer to both refugees and asylum seekers, as these people can be considered part of the broader category of externally displaced persons.

Global mass displacement seems to be predominantly caused by increases in conflict in certain Middle Eastern and Northern African countries (particularly in the Syrian Arab Republic and South Sudan), and this rather unprecedented and rapid influx of displaced people is now being referred to as the "refugee crisis". Political and media discourses on this topic center around how to best balance the need for safe border control measures, with internationally recognized laws that promote humanitarian environments for individuals seeking asylum (Ostrand, 2015). Many developed countries have recently implemented more strict border control policies, which has resulted in an estimated $86 \%$ of refugees currently 
reside in lower- and middle- income countries, where they remain close to conflict (UNHCR, 2016).

Taken together, when considering the global influx of refugees in combination with the introduction of restrictive refugee-relevant policies by the host countries, it is apparent that the refugee crisis is a global struggle that constitutes several ongoing challenges. The challenges will tend to revolve around the successful integration of refugees into the host culture, and promoting a harmonious co-existence with locals. Previous research has demonstrated that a vital component of the successful acculturation of refugees into their host culture is the social attitudes of the locals towards them (Berry, 1997). Thus, in this paper we systematically locate the available data on social attitudes towards refugees, and then identify variables that correlate with these attitudes and meta-synthesize the strength of their relationships.

\section{Attitudes Towards Refugees}

A wide body of research has begun documenting patterns of social attitudes towards refugees. Specifically, research has revealed pervasive and typically negative attitudes towards refugees (for reviews, see Haslam and Holland, 2012). Although much of the research on attitudes has come from Australia, research has yielded similar results in other countries, such as Great Britain (Crawley et al., 2013), Canada (Louis et al., 2013), Malaysia (Cowling and Anderson, 2018), and Turkey (Yitmen and Verkuyten, 2017). These negative attitudes are concerning as public attitudes play a role in voting behaviors and Government policies towards the management of refugees (Verkuyten, 2004, Hartley and Pedersen, 2007).

Research in this area has largely focused on identifying the various antecedents of these attitudes. For example, a recent meta-analysis of the Australian literature on this topic identified a series of individual differences (i.e., demographic variables and ideological factors) that significantly correlated with attitudes towards refugees (Anderson and Ferguson, 
2018a). However, given the high levels of documented prejudice towards refugees globally, and the increased likelihood that the refugee crisis shows no signs of relenting, a review of the global data is warranted. Conducting such a review is the major aim of this paper, and below we discuss the major prejudice-relevant factors that emerged whilst reviewing this literature.

\section{Demographic correlates}

Demographic differences are reliable and well-established predictors of inter-group attitudes (Hodson and Dhont, 2015). A study by Pedersen and colleagues (2005) was the first to establish a link between demographic variables and attitudes towards refugees. In this study, the researchers simultaneously validated the Attitudes Towards Asylum Seekers Scale (ATAS) while showing that attitudes towards asylum seekers are linked to differences in levels of national identification, gender, age, political orientation, and education.

Studies that followed verified a range of demographic predictors, with the literature typically revealing more negative attitudes towards refugees tend to be held by men (e.g., Anderson 2017), those who are older (e.g., Mckay et al., 2012), are highly nationally identified (Nickerson and Louis, 2008), are politically conservative (e.g., Anderson, Koc, Hartley, and Pedersen, 2018), are religiously affiliated (e.g., Deslandes \& Anderson, 2018), and have lower levels of education (e.g., Greenhalgh and Watt, 2014), relative to their counterparts (i.e., women, the younger, the politically liberal, the lesser nationally identified, the non-religiously affiliated, and the educated).

\section{Ideological correlates}

Individual differences in ideological beliefs have been demonstrated to underpin attitudes towards refugees. For example, Duckitt and Sibley's (2010) have proposed a dual process model of prejudice which comprises the two ideology-based predictors of social dominance orientation (SDO: a competition-based cognitive motivational process that 
promotes intergroup inequality by endorsing hierarchical social systems; Sidanius and Pratto, 1999) and right-wing authoritarianism (RWA: a threat-based cognitive motivational process that promotes the authoritarianism and uniformity of society; Altemeyer, 1991). Although these two factors are highly correlated, a body of well-established evidence supports the theory by demonstrating that each independently predict general prejudice (e.g., Akrami and Ekehammar, 2006), as well as refugee-specific prejudice (e.g., Anderson, 2016, Study 2, Nickerson and Louis, 2008). Indeed, in their meta-analytic review, Anderson and Ferguson (2018a) suggested that the factors in Duckitt and Sibley's (2010) dual process model of prejudice might best account for prejudice towards refugees (at least in Australia), as this model proposes that the dual cognitive motivational processes of threat and competition, drives individuals who possess higher levels of RWA (threat-based) or SDO (competitionbased) to hold prejudicial attitudes towards out-groups.

A limited number of Australian based studies have also considered the roles of social justice principles. Social justice principles are described as individuals' orientations towards social justice (Brickman et al., 1981). These principles distinguish an individual focused and equity-based micro justice orientation (the belief that a fair society is one where individuals are allocated resources in accordance with their contributions to society) from a societalfocused and equality-based macro justice orientation (the belief that a fair society is one where resources are equally distributed amongst all). The research has demonstrated (after statistically controlling for RWA and SDO) that macro justice principles predicted positive attitudes towards refugees, while micro justice principles were not found to be predictive of attitudes (e.g., Anderson, 2016, Study 2, Anderson et al., 2015).

Threat perception variables

Understandings of prejudice based in social perceptions were first proposed by Stephan and Stephan's (2000) in their Integrated Threat Theory. This theory posits two types 
of threat - symbolic and realistic threats. Certain features of social out-groups might exacerbate perceptions of the out-group as threatening, and this theory posits that this threat influences behaviors and attitudes, typically resulting in increases in prejudice. In the specific case of refugees, symbolic threats might comprise refugees being perceived as incompatible with the values and national identity of the country in which they resettle. Conversely, realistic threats might comprise refugees being perceived as threatening the economic and political power of the country in which they resettle.

Studies suggest that these perceptions are being fueled by false beliefs and unfounded fear that is driven by media misrepresentations of refugees as being threatening to society, due to their supposed illegality and links with terrorism (Augoustinos and Quinn, 2003). A study by Schweitzer et al. (2005) demonstrated how Australians who perceived refugees as posing both symbolic and realistic threats to Australia were more likely to hold unfavorable views, and be in support of stricter border control policies.

\section{Emotion variables}

In line with Lazarus's (1991) appraisal theory of emotions, which suggests that emotions are elicited by our appraisals (i.e., interpretations, evaluations) of various events and situations, researchers have argued that prejudice can manifest as the expression and possession of different emotions (Tapias et al., 2007).

In line with these findings, a small body of research has investigated the emotions elicited by the refugee crisis, and the subsequent role of these emotions in influencing attitudes. Empathy in particular has been demonstrated to be predictive of positive attitudes towards refugees. An Australian study carried out by Hartley and Pedersen (2007) investigated the role of empathy in influencing attitudes. They found highly empathetic individuals to be in support of more tolerant and inclusive legislative policies towards the admission of refugees in comparison to less empathetic individuals. Researchers have argued 
that this is because empathy is the main psychological process in which in-group and outgroup distinctions are bridged (e.g., Davis, 2004). Therefore, empathetic individuals are argued to be more concerned with the wellbeing of others, and thus support efforts to help the disadvantaged (Stephan and Finlay, 1999). In addition, recent research by Koc and Anderson (2018) has revealed that intergroup anxiety is in an important emotion-based variable that is a strong predictor of attitudes towards Syrian refugees. Although a relatively small line of research, these preliminary findings show potential for the consideration of emotion variables in designing prejudice-reduction interventions.

The current literature suggests that emotions such as empathy and intergroup anxiety may influence attitudes towards refugees. In the current study, we aimed to locate and examine these emotions, and any others emotions that have been explored in the literature on attitudes towards refugees.

\section{The Current Study}

In their recent meta-analysis, Anderson and Ferguson (2018a) meta-analyzed Australians' demographic and ideological correlates of attitudes towards asylum seekers. A growing body of international research has also sought to establish various correlates of these attitudes towards refugees. Therefore, this current study aims to extend the work of Anderson and Ferguson by systematically aggregating globally available data of the prejudice-relevant correlates of attitudes towards refugees, and quantitatively synthesizing these findings. The major aim of this paper is to estimate the effect size estimates for the relationships between refugee-attitudes and prejudice-relevant correlates.

We also test the potential moderating role of two factors. First, large amounts of research in this domain is being conducted in Australia, and indeed the afore mentioned meta-analysis focused only on Australian data, and thus we are interested in knowing if Australian samples produce different effect sizes from non-Australian samples. The 
Australian context is unique to that of other countries that host refugees. This is because, even though Australian's have relative little contact with refugees (due to the country's geographical isolation and relatively small refugee intake), levels of negative attitudes towards refugees are high (Haslam and Holland, 2013). Further, public discourse about refuges is particularly negative (e.g., Gale 2004; Pickering, 2001) and government policy towards refugees is particular punitive (e.g., policies of mandatory detention and denial of permanent settlement to refugees arriving my boat; Hartley, Anderson, \& Pedersen, 2018). As such, it is not clear if research on attitudes towards refugees in this context is also applicable to other countries, or if the results may vary by sample location ${ }^{1}$.

In addition, we always investigated whether publication status moderated the observed effect sizes. There are large amounts of unpublished data exploring relationships with attitudes to refugees, and thus we are interested in knowing if the publication status of the data produces different effect sizes (i.e., a test of publication bias). In addition, we will use moderation analyses to test if effect sizes differ depending on the year the data was published.

\section{Method}

\section{Search Strategy}

We developed the search strategy detailed below, and have reported the method and findings based on the relevant sections of the PRISMA guidelines (Moher et al., 2009). A systematic search was conducted in April, 2017 across the following five databases: Web of Science, PsycINFO, PsycEXTRA, Proquest Psychology Collection, and EBSCO Psychology, and Behavioral Sciences Collection. Search terms were selected to appropriately identify the concepts of refugees and attitudes. Across databases, the following terms were used:

\footnotetext{
${ }^{1}$ Other moderators based on geographic factors could also considered as part of the analysis (e.g., whether countries were transit migration or installation countries). However, the extant research does currently include sufficient research to conduct such as analysis.
} 
(refugee* OR asylum* OR 'political asylum*') AND (attitude* OR belief* OR opinion* OR social perception* OR judg* or prejudice*). Only results in the English language were considered and no date restrictions were set. Requests were also made for unpublished data through the Society for Australasian Social Psychologists, the Society for Personality and Social Psychology, and the European Association for Social Psychology. Finally, established researchers in the field were contacted for unpublished data or data based in dissertations.

\section{Screening and Inclusion Criteria}

Records identified using the above search strategy underwent two phases of screening. In the first phase, titles and abstracts were examined for references made to measuring attitudes towards refugees. Records deemed relevant at this stage were then submitted to full text screening to determine eligibility for inclusion in the meta-analysis. Records had to meet the following inclusion criteria to be eligible: (a) include a measure of attitudes towards refugees or asylum seekers; (b) include a measure of at least one prejudicerelevant correlate; and (c) present original empirical quantitative data.

\section{Data Extraction}

The following data were extracted from eligible records: information regarding the sample size and the country of origin of the participants and details of the instruments used to assess attitudes towards refugees (ATAS, feeling thermometer etc.). Where possible, raw bivariate correlations between the measured attitude and any relevant correlates were extracted directly from the papers (Pearson's product-moment correlation coefficients for metric variables [e.g., age]; Spearman's rank correlation coefficient for categorical variables [e.g., gender]). When relevant variables were included, but correlations were not reported, the authors were contacted and requests were made for this data. Obtained correlations were coded so that positive correlation coefficients reflected increases in negative attitudes. To 
conduct sub-group moderation analyses, sample type (student vs. non-student) and the publication status (vs. unpublished) of the studies were extracted.

\section{Statistical Procedures}

Statistical analyses was conducted using Comprehensive Meta-Analysis Version 3.0 (Borenstein et al., 2014), following procedures outlined in (Borenstein et al., 2009). For all analyses, the extracted correlations were transformed into Fisher's $Z$ scores. Separate metaanalyses were conducted to estimate the effect size of the relationship between attitudes and each prejudice-relevant correlate. Tests to measure the presence of heterogeneity between effect sizes were conducted by calculating Cochran's $Q$ statistics. To examine the proportion of heterogeneity attributed to true differences rather than sampling error between studies, the $I^{2}$ statistic $^{2}$ was assessed. Two sub-group analyses were conducted to test whether effect sizes differed as a function of the proposed categorical moderators: (a) sample location (Australia vs. elsewhere), and (b) publication status (published vs. non-published). In addition, we conducted a meta-regression to test is effect sizes changed across time (based on year of publication).

\section{Results}

The results of the systematic search and subsequent screening process are presented in Figure 1. Overall, 56 records reporting 70 studies $(N=13,720$ participants $)$ were eligible for inclusion. Of the 70 studies, data from 27 (39\%) were unpublished and 43 (61\%) were published, while data from 49 (70\%) studies were from Australia, and data from 21 were collected elsewhere (six from the United States, three from Israel, two from the Netherlands, Turkey, England, and Germany, and single studies from India, Italy, Croatia, and one international study. In total, 269 effect sizes were extracted. The total sample size for each

\footnotetext{
${ }^{2}$ According to Higgins and Green (2011), $I^{2}$ values between $40 \%$ - $60 \%$ represent small heterogeneity, $60 \%$ $75 \%$ represent moderate heterogeneity and $75 \%-100 \%$ represent considerable heterogeneity. Research suggests that heterogeneity above $75 \%$ can be problematic (Higgins, Thompsan, Deeks \& Altman, 2003).
} 
correlate, the number of effects aggregated, the average effect size estimates and measures of heterogeneity estimates are presented in Table 1.

\section{FIGURE 1 ABOUT HERE}

\section{Demographic Factors}

Age. The average effect size estimate was non-significant, which suggests no systematic relationship between age and attitudes towards refugees. This estimate did not vary as a function of publication year $Q(1)=0.01, p=.930$.

Education. The average effect size estimate was a small but significant negative correlation between levels of education and attitudes, which suggests that lower levels of education are associated with increases in prejudice. This estimate did not vary as a function of publication year $Q(1)=0.00, p=.975$.

Gender. The average effect size estimate was a small but significant positive correlation between gender and attitudes, which suggests that being male is associated with reporting more negative attitudes, than being female. This estimate did not vary as a function of publication year $Q(1)=1.18, p=.277$.

National identification. The average effect size estimate was a small but significant positive correlation between national identification and attitudes, which suggests that higher levels of national identification are associated with increases in prejudice. This estimate varied as a function of publication year $Q(1)=10.37, p=.001$. Specifically, as the year of publication increased, the strength of the effect size estimate weakened $(\beta=-0.022[95 \% \mathrm{CI}$ $=-0.04,-0.09], p=0.001)$.

Political orientation. The average effect size estimate was found to be a small but significant positive correlation between political orientation and attitudes, which suggests that 
political conservatism is associated with increases in prejudice. This estimate did not vary as a function of publication year $Q(1)=0.36, p=.548$.

Religious affiliation. The average effect size estimate was found to be a small but significant positive correlation between religious affiliation and attitudes, which suggests that religious affiliation is associated with increases in prejudice. This estimate did not vary as a function of publication year $Q(1)=0.71, p=.399$.

\section{Ideological Variables}

$R W A$. The average effect size was a moderate and significant positive correlation between RWA and attitudes, which suggests that higher levels of RWA are associated with increases in prejudice. This estimate did not vary as a function of publication year $Q(1)=$ $0.27, p=.602$.

$S D O$. The average effect size estimate was a moderate and significant positive correlation between SDO and attitudes, which suggests that higher levels of SDO are associated with increases in prejudice. This estimate did not vary as a function of publication year $Q(1)=0.02, p=.885$.

Macro justice principles. The average effect size estimate was a moderate and significant negative correlation between macro justice principles and attitudes, which suggests that endorsements of macro justice principles are associated with decreases in prejudice. This estimate did not vary as a function of publication year $Q(1)=0.73, p=.394$.

Micro justice principles. The average effect size estimate was non-significant between micro justice principles and attitudes, suggesting no systematic relationship. This estimate did not vary as a function of publication year $Q(1)=0.70, p=.401$. 


\section{Threat Perception}

Symbolic Threat. The average effect size estimate was a strong and significant positive correlation between symbolic threat and attitudes, which suggests that perception of refugees as symbolic threats are associated with increases in prejudice. Meta-regression exploring is this effect varied as a function of publication year could not be conducted, because there were not enough studies for the number of covariates in the model.

Realistic Threat. The average effect size estimate was a strong and significant positive relationship between realistic threat and attitudes, which suggests that perception of refugees as realistic threats are associated with increases in prejudice. Again, meta-regression could not be conducted, because there were not enough studies for the number of covariates in the model.

\section{Emotion Variables}

The systematic search was conducted with the intention of locating studies that had examined the relationship between attitudes towards refugees and any emotion. However, the only studies located that met the inclusion criteria for the analysis were those specifically measuring empathy. Thus, we are only able to present results pertaining to empathy, and not other emotions. The average effect size estimate was a non-significant correlation between empathy and attitudes, suggesting no systematic relationship. This effect did not vary as a function of publication year $Q(1)=1.73, p=.188$. 


\section{Heterogeneity}

Results revealed that Cochran's $Q$ was statistically significant for all variables. To test the extent of this observed heterogeneity, $I^{2}$ statistics were examined. The results revealed that the level of observed heterogeneity was moderate for gender and national identification. However, the observed level of heterogeneity for all other prejudice-relevant correlates was found to be large. These results indicate that the variability seen between effect sizes stems from true differences between the studies and highlights the possibility of moderating variables.

\section{Moderator Analyses}

Sample type. To determine whether the location of the sample (data from Australia vs. elsewhere) played a moderating role, a subgroup analysis was conducted on all variables (see Table 2). Sample location moderated the effect size estimates for the relationships between attitudes and some demographic factors (gender, education level, national identification), and threat perception variables (both symbolic and realistic threats). Each of these relationships was stronger when the data was from an Australian sample with the exception of national identification, which was stronger when the data was from elsewhere. The effect size estimates did not vary as a function of the sample's location for the relationships between prejudice and either ideological or emotion variables.

Publication status. To test for the presence of publication bias, another sub-group analysis using publication status as a moderator was conducted (see Table 2). The results revealed that publication status significantly moderated the observed effect sizes for symbolic and realistic threat. In both cases, the effect sizes from published studies were significantly larger than the effect sizes from unpublished studies. This suggests the possible presence of publication bias for these variables, although the limited number of effect sizes in this 
analysis is worth considering when interpreting this finding. However, the subgroup analyses were non-significant for all other variables, indicating no evidence of publication bias.

\section{TABLE 2 ABOUT HERE}

\section{Discussion}

This paper presents a meta-analytic review of studies that investigated prejudicerelevant correlates of attitudes towards refugees. To do so, quantitative research studies were obtained through a systematic database search, and calls for unpublished data. The data of these studies were extracted and statistically synthesized. In all, it was found that being male, being religiously affiliated, having less education, being politically conservative, being highly nationally identified, being high in RWA and SDO, and perceiving refugees as being symbolic and realistic threats correlated with negative attitudes, while the endorsement of macro justice principles correlated with positive attitudes. These findings are detailed below.

\section{Demographic Factors}

The results revealed five demographic factors, which were weakly but significantly correlated with attitudes. Specifically, it was found that being politically conservative, highly nationally identified, less educated, religiously affiliated and being male were factors that significantly correlated with increases in negative attitudes towards refugees. These demographic factors are well-known correlates of general prejudice (Hodson and Dhont, 2015), as well as refugee-specific prejudice (e.g., Anderson, 2016). Although typically found to correlate with prejudice, age was not systematically related to attitudes toward refugees. It is worth highlighting that some of these demographic variables are over-encompassing categories - for example political orientation could have been operationalized along multiple dimensions rather than a single dimension (e.g., orientation on social vs economic issues) and 
religion could be quantified as a multi-categorical (e.g., Christian vs. Muslim. Vs Buddhist, etc) or an individual difference (i.e., religiosity - see Allport, 1954, Anderson, 2015). We note that we were restricted to analyzing these variables in the same manner that they have been presented in the extant literature, yet concede that these factors should be considered with more nuance in future research.

\section{Ideological Variables}

Three ideological variables were moderately correlated with attitudes. Specifically, increases in RWA and SDO were found to be associated with increases in negative attitudes, while endorsements of macro justice principles were associated with increases in positive attitudes. It is suggested that the mechanism behind increased prejudice associated with high levels of RWA and SDO, is driven by threat and competition- based cognitive motivational processes respectively (Duckitt and Sibley, 2010, Duckitt, 2006, Duckitt, 2001). Scholars argue that these ideological variables are dispositions that constantly oscillate as they interact with threatening circumstances to produce prejudice (Stenner, 2005), and indeed they are the most commonly researched predictors of attitudes towards refugees (Anderson and Ferguson, 2018a).

The endorsement of macro justice principles was the only identified variable in this review to be predictive of positive attitudes. This is argued to be because macro justice principles are driven by principles of equality, that endorse a belief system in which the distribution of available resources should be allocated towards those who are in greater need (Anderson, 2016, Study 2, Anderson et al., 2015). Although theorized to be linked to punitive social attitudes, micro justice principles were found to be uncorrelated with attitudes towards refugees. Research has found that the endorsements of micro justice principles are often linked with possessing meritocratic beliefs (Zdaniuk and Bobocel, 2011). Anderson and colleagues (2015) argue that micro justice principles are unrelated to (Australian) attitudes 
towards refugees, as refugees are not visible to wider society, and thus are unable to prove their worth and merit.

\section{Threat Perception Variables}

Threat perception was identified as being the strongest correlate of negative attitudes (though given the limited size of the literature, this claim is made with a level of caution). Threat perceptions are often the result of false beliefs, usually attributed to media influence that reinforces the threat that refugee's pose to national identity and security. For example, a study by McKay and colleagues (2012) found that many Australians viewed refugees as a threat to Australia because of their supposed links with Islam and terrorism. Perceived symbolic and realistic threat has been linked with increasing anxiety and intergroup tensions that results in violent conflicts and discrimination against socially vulnerable groups. The findings of this meta-analysis suggest that, at least based on the limited available data, threat perceptions appear to be the strongest driving force behind refugee-specific prejudice.

\section{Emotion Variable}

No relationship existed between empathy and attitudes (the only emotion variable to be identified as a correlate by our search strategy), which is inconsistent with research demonstrating empathy's ability to foster positive attitudes towards socially disadvantaged groups. A plausible explanation might lie in theories of dehumanization (Haslam, 2006, Leyens et al., 2000), and specifically the media's role in dehumanizing refugees (Deslandes \& Anderson, 2018, Greenhalgh and Watt, 2014, Louis et al., 2013, Mckay et al., 2012). Specifically, by portraying refugees as less than fully human, individuals legitimize punitive policies pertaining to their treatment and create a need to psychologically distance one's self from refugees (Anderson, Koc, Deslandes, Hartley, \& Pedersen, 2018). For example, Klocker and Dunn (2003) conducted an analysis of newspapers reporting's on refugees and found mostly negative representations of refugees, with newspapers actively derogating refugees by 
referring to the social group with dehumanizing terminology, such as 'uncontrollable' and 'demanding'. The continuous media portrayal of refugees as lacking human qualities creates problems in that the morally questionable ways of treating refugees becomes justifiable.

As only a small number of studies $(n=4)$ have investigated the link between empathy and prejudice, researchers should further investigate this relationship, as relevant research in other domains has provided promising results of the positive outcomes associated with empathy-based interventions against prejudice.

\section{Heterogeneity}

It is worth noting the moderate to high heterogeneity for all variables. While high levels of heterogeneity often warrant concern, it is likely that the diversity and differences between the studies may have caused these high levels. In particular, the nature of a body of research that explores socio-psychological phenomenon will typically use a range of sample types, employ different measures, and use different research designs. For example, data were supplied by participants who varied dramatically in their location (e.g., Australia vs. Europe vs. Asia, etc.). As a function of sample location, there exist differences in the demographic makeup of the citizens, ranging from differences in ethnicity, race, cultural beliefs, traditions, and the understanding and interpretations of issues/constructs relating to refugees. Furthermore, countries differ in their management of the refugee crisis, including political policy orientations regarding the number of refugees hosted, the origin of these refugees, etc.

The ways in which variables were quantified across studies may have also contributed to the observed heterogeneity. For example, across studies, religious affiliation was measured dichotomously (religiously affiliated or not). It has been argued that religion is a complex construct that consists of many different dimensions, ranging from individual differences in strength of dedication, to degree of belief. Therefore, it is argued that a better way to understand the link between religion and prejudice is to consider individual religiousness, or 
'religiosity', in order to identify what aspect of religion is directly related to prejudice (Allport, 1954, Anderson, 2015). There was also an observed difference in the way studies were conducted. Most noticeably, there were various measures of attitudes that were employed across studies and countries. For example, most Australian based studies used the ATAS because it was designed based on an Australian context in regards to issues pertaining to asylum seekers (Pedersen et al., 2005). Consequently, most non-Australian studies relied on other measures, such as original scales to measure attitudes. These differences likely contribute to the heterogeneity revealed by the meta-analysis.

Finally, it is also worth highlighting that certain effect sizes in this meta-analysis (i.e., macro justice principles, empathy, symbolic and realistic threats) were estimated based on a small number of studies. It has been argued that the $I^{2}$ statistic is unreliable when there is a small number of studies $(<10)$ due to a loss of statistical power (Huedo-Medina et al., 2006). This adds another layer of complexity when making interpretations about these variables and the observed heterogeneity, and thus such interpretations should be made cautiously.

\section{Moderator Analyses}

Sub-group analyses were conducted in an attempt to identify potential moderators. To determine the presence of sample bias, a sub-group analysis was conducted using sample location (data from Australia vs. elsewhere) as a moderator. The results revealed that sample location did not significantly moderate most effect sizes, with the exception of some demographic variables and the threat perception variables. Specifically, the effect size estimates of the relationships between prejudice with both gender and education were stronger from Australians than from samples from other locations. This was also true of the effect size estimates of the relationship between prejudice and both symbolic and realistic threats (although we note that each of these effects were based on a small amount of effects). Conversely, the effect size estimate for the relationship between prejudice and national 
identification was weaker from Australians than from samples from other locations. We cannot pose theoretical reasons for predicting these differences, however, we are not surprised by these findings given that the context of refugee prejudice in Australia is different on many levels to other places in the world. For example, Australia is geographically isolated, refugees cannot arrive by foot (they must fly or sail), and Australia hosts relatively few asylum seekers and refugees in comparison to other countries that are located geographically closer to areas of conflict from where the refugees might be fleeing. Finally, there were not enough effects from other single location (e.g., Asia, Europe, etc.) to compare Australian data to any other single location, although as research in this field continues to emerge, future meta-analytic reviews in this area can re-assess locality-based differences.

To determine the presence of publication bias, a sub-group analysis was conducted using publication status (published vs. unpublished) as a moderator. The results revealed that publication status did not significantly moderate the effect sizes for most variables, except for symbolic and realistic threat, and there was no evidence of $p$-hacking (based on the findings of the $p$-curve analysis). However, again we acknowledge that only number of effects have explored symbolic and realistic threat (1 published, 2 unpublished), and thus synthesizing these findings might be less statistically stable than if the meta-analysis had a larger number

of effects. Given the strength of the reported relationships that refugee-prejudice has with these variables, we suggest researchers in this field further investigate the role that threat appears to have in driving refugee-antipathy.

\section{Theoretical and Practical Implications}

There are theoretical and practical implications that can be drawn from the findings of this meta-analytic review. These findings provide continued support for various theoretical accounts of intergroup relations. For example, as expected, ideological variables and perceptions of threat impact negative attitudes (DPM; Duckitt and Sibley, 2010; Integrated 
threat theory, Stephan and Stephan, 2000), and a variety of demographic factors reliably predict increases in anti-refugee sentiment. Based in theories of social identity (e.g., Tajfel and Turner, 1979), it is likely that many of these factors are exacerbating in/out-group salience (e.g., national identification), which then results in increases in negative attitudes (although, this assumption remains untested). It is worth highlighting that these findings largely replicate the wider literature on prejudice, however, given that there are specific features of refugees as attitude-objects that differ from other prejudice targets (e.g., there are a variety of reasons for entering this social category, the category is non-essential, etc.), more research is warranted to best understand the unique aspects of this prejudice type, and what variables are moderating these relationships.

In addition, these findings have several practical implications. For example, they provide direction for ameliorating intergroup relations between refugees and host country locals. For example, interventions with the aim of increasing tolerance reducing prejudice against this group could use these findings (a) to identify certain social groups that need targeting (e.g., individuals who are politically conservative, nationalistic, etc.) and (b) to inform the type of content that should comprise the interventions (e.g., focusing on reducing misinformation that suggests threat promoting endorsement of macro-justice principles, etc.). Recent research has begun to explore the role of prejudice in a variety of applied outcomes, for example negative refugee attitudes have been linked to support for punitive policies for the treatment of refugees (e.g. Hartley et al., 2018) and perceptions that asylum seekers are avoiding integrating to the host culture (Koc \& Anderson, 2019). Continued work in this sphere is necessary to understand the consequences of prejudice for refugees, not only in terms of their negative impact of being targeted, but for the practical aspects such as how it impacts their treatment by host culture members.

\section{Limitations}


There are limitations of both the literature within this area of research, and this review, which warrants discussion. Regarding the literature, it was observed that a large proportion of the data in this meta-analysis had been collected in Australia - given Australia's relatively unique conditions (i.e., geographic isolation, distanced from typical countries of refugee origin, limited refugee intake, etc.), this poses a problem in that the refugee-prejudice data represented in the literature might not be an accurate reflection of global refugee-prejudice relationships. Although a limited amount of data from more heavily impacted countries were identified by this systematic search, the literature would benefit from ongoing research from countries whose residents are more directly and severely impacted, from those countries hosting large amounts of refugees.

A second major limitation pertains to the language used around the targets of these prejudice. Specifically, while asylum seekers and refugees by definition are two distinct social categories, in wider society the terms tends to be used interchangeably. It was observed that many studies used in this meta-analysis did not explicitly differentiate the difference between refugees and asylum seekers (not to mention other subordinate categories - e.g., internally displaced persons, returned refugees, etc.), and instead, employed one of the terms to be an overarching category to refer to both social categories. This might accurately reflect an ecologically valid use of these social category labels, however, whether there is a need to distinguish these categories in research is an empirical question, which is confounding the internal validity of this literature.

Finally, there are related attitude-target constructs that might also be tapping attitudes towards refugees that were not included in this analysis. For example, we did not include attitudes towards forced vs. voluntary migration (e.g., Verkuyten, Mepham, \& Kros, 2018) or asylum seeker/refugee-relevant policies (e.g., Hartley et al., 2018). These distinct, yet related constructs might be considered in future work in this field. 


\section{Concluding Remarks and Future Directions}

This paper presented a systematic review of the available research investigating attitudes towards refugees. The resulting meta-analysis identified a series of significant relationships between attitudes and demographic, ideology-based, and threat perception variables. These findings contribute to the growing body of knowledge that aims to understand the antecedents of prejudice towards this socially vulnerable group.

There now an established body of research on correlates of prejudice towards refugees in a broad sense, however, there are several issues that have been identified that could act as a catalyst for future work. First, little is known about prejudice towards different refugee-groups, including whether or not differences exist based on their state of origin (e.g., African vs. Asian refugees), their own social group memberships (e.g., religious, ethnic, etc.), and their method of arrival to the host culture (e.g., boat arrivals vs settlement from camps, etc.). Second, little research is being conducted in countries that are most effected by the refugee crisis, including those neighboring the areas of conflict causing the displacement and those hosting the majority of the world's refugees. Third, there is a lack of longitudinal data available exploring changing patterns of attitudes towards refugees. And finally, little research is exploring the mechanisms that underlie these relationships will would allow an empirically-based generation of refugee-specific prejudice interventions, aimed at improving intergroup relations between refugees and locals. 


\section{References}

NB: References marked with an * were included in the meta-analysis

AKRAMI, N. \& EKEHAMMAR, B. 2006. Right-wing authoritarianism and social dominance orientation: Their roots in big-five personality factors and facets. Journal of Individual Differences, 27, 117-126.

ALLPORT, G. 1954. The nature of prejudice, Cambridge, MA, Addison-Wesley.

ALTEMEYER, B. 1991. Right-wing authoritarianism., Winnipeg, Canada, University of Manitoba Press.

*ANDERSON, J. R. 2015. The social psychology of religion: Using scientific methodologies to understand religion. In: MOHAN, B. (ed.) Constructions of Social Psychology. Baton Rouge, CA: inScience Press.

*ANDERSON, J. R. 2016. Implicit and explicit attitudes toward asylum seekers: Demographic and ideological correlates. Australian Psychologist, 1-11.

*ANDERSON, J. R. 2017a. The moderating role of socially desirable responding in implicit-explicit attitudes toward asylum seekers. International Journal of Psychology.

*ANDERSON, J. R. 2017b. The prejudice against asylum seekers scale: Presenting the psychometric properties of a new measure of classic and conditional attitudes. Journal of Social Psychology.

*ANDERSON, J. R. \& CHEERS, C. 2018. Does the dark triad predict prejudice?: The role of Machiavellianism, psychopathy, and narcissism in explaining negativity toward asylum seekers. Australian Psychologist. doi:10.1111/ap.12283

*ANDERSON, J. R. \& FALOMIR-PICHASTOR, J. M. 2015a. Attitudes toward asylum seekers: The role of meritocracy and social norms Unpublished manuscript.

*ANDERSON, J. R. \& FALOMIR-PICHASTOR, J. M. 2015b. Social normative influence moderates explicit-implicit attitudes toward asylum seekers. Unpublished manuscript.

ANDERSON, J. R. \& FERGUSON, R. 2018. Demographic and ideological correlates of negative attitudes toward asylum seekers: A meta-analytic review. Australian Journal of Psychology, 70, 18-29.

*ANDERSON, J. R., FERGUSON, R., DESLANDES, C. 2018. Emotional reponse pathways to attitudes toward asylum seekers. Manuscript submitted for publication.

*ANDERSON, J. R., FERGUSON, R. \& CHAPMAN, J. E. 2016a. Reconcidering the role of right-wing authoritariansm in attitudes toward asylum seekers. Unpublished manuscript.

*ANDERSON, J. R., FERGUSON, R., ROSSEN, I. \& STUART, A. 2018. Can the moral foundations predicts attitudes and behaviours toward asylum seekers. Manuscript submitted for publication..

*ANDERSON, J. R., KOC, Y., HARTLEY, L., \& PEDERSEN, A. 2018. Differing operationalization of political ideologies have different pathways to prejudice against asylum seekers. Manuscript in preparation for submission. 
*ANDERSON, J. R., KOC, Y., DESLANDES, C., HARTLEY, L., \& PEDERSEN, A. 2018. Dehumanization processes predicts support for asylum seeker policies. Manuscript in preparation for submission.

*ANDERSON, J. R., STUART, A. \& ROSSEN, I. 2015. Not all negative: Macro justice principles predict positive attitudes towards asylum seekers in Australia. Australian Journal of Psychology, 67, 207-213.

AUGOUSTINOS, M. \& QUINN, C. J. 2003. Social categorization and attitudinal evaluations: Illegal immigrants, refugees, or asylum seekers? Augoustinos, M., \& Quinn, C.J. (2003). Social categorization and attitudinal evaluations: Illegal immigrants, refugees, or asylum seekers? Nouvelle Revue de Psychologie Sociale, 2(1): 29-37, 2, 29-37.

*BARTLETT, S. \& PEDERSEN, A. 2016. The just world effect: The relationship between belief in a just world, moral disengagement and stance on asylum seeker policy. Manuscript under review.

BERRY, J. W. 1997. Immigration, acculturation, and adaptation. Applied Psychology in Criminal Justice, 46, 5-34.

BORENSTEIN, M., HEDGES, L., HIGGINS, E. \& ROTHSTEIN, H. R. 2014. Comprehensive Meta-Analysis (Version 3.0). Englewood, NJ: Biostat.

BORENSTEIN, M., HEDGES, L., HIGGINS, J. \& ROTHSTEIN, H. 2009. Introduction to MetaAnalysis, Chichester, UK, John Wiley \& Sons.

BRICKMAN, P., FOLGER, R., GOODE, E. \& SCHUL, Y. 1981. Microjustice and Macrojustice. In: LERNER, M. \& LERNER, S. (eds.) The Justice Motive in Social Behavior. Springer US.

*CANETTI, D., SNIDER, K. G., PEDERSEN, A. \& HALL, B. J. 2016. Threatened or threatening? How ideology shapes asylum seekers' immigration policy attitudes in Israel and Australia. Journal of Refugee Studies, 29, 583-606.

COWLING, M. \& ANDERSON, J. R. 2018. The role of religion in explaining attitudes towards Christian and Muslim asylum seekers in Malaysia. Manuscript under review.

CRAWLEY, H., DRINKWATER, S. \& KAUSER, R. 2013. Variations in attitudes towards refugees: Evidence from Great Britain [Online]. Available: http://www.creammigration.org/publ_uploads/CDP_26_13.pdf [Accessed].

*CROSTON, J. \& PEDERSEN, A. 2013. 'Tell me what I want to hear': Motivated recall and attributions in media regarding asylum seekers. Australian Journal of Psychology, $65,124-133$.

*CROUCAMP, C. J., O'CONNOR, M., PEDERSEN, A. \& BREEN, L. J. 2016. Predicting community attitudes towards asylum seekers: A multi-component model. Australian Journal of Psychology.

*DESLANDES, C., \& ANDERSON, J.R. 2018. Explicit and implicit dehumanization of asylum seekers in Australia. Manuscript under review.

DESLANDES, C., \& ANDERSON, J.R. 2018. Religion and prejudice towards immigrants and refugees: A meta-analytic review. The International Journal for the Psychology of Religion. 
DAVIS, M. 2004. Negotiating the border between self and other, Melbourne, Australia, Cambridge University Press.

DUCKITT, J. 2001. A dual-process cognitive-motivational theory of ideology and prejudice.

DUCKITT, J. 2006. Differential effects of right-wing authoritarianism and social dominance orientation on outgroup attitudes and their mediation by threat from and competitiveness to outgroups. Personality and Social Psychology Bulletin, 32, 684-696.

DUCKITT, J. \& SIBLEY, C. G. 2010. Personality, ideology, prejudice, and politics: A dualprocess motivational model. Journal of Personality, 78, 1861-1894.

*ESCHERT, S., KNAUSENBERGER, J. \& DIEHL, M. 2017. Are all conservatives alike in Germany? Motivation bases of cultural and economic conservatism and consequnces for the debate on the refugee crises. Manuscript submitted for publication.

GALE, P. (2004). The refugee crisis and fear: Populist politics and media discourse. Journal of Sociology, 40(4), 321-340. doi:10.1177/1440783304048378

*GREENHALGH, E. M. \& WATT, S. E. 2014. Preference for consistency and value dissimilarities in dehumanization and prejudice toward asylum seekers in Australia. European Journal of Social Psychology.

*GREENHALGH, E. M., WATT, S. E. \& SCHUTTE, N. S. 2015. Mechanisms of moral disengagement in the endorsement of asylum seeker policies in Australia. Ethics \& Behavior, 25, 482-499.

*GREGUROVIĆ, M., KUTI, S. \& ŽUPARIĆ-ILJIĆ, D. 2016. Attitudes toward immigrant workers and asylum seekers in eastern Croatia: Dimensions, determinants and differences. Migracijske i ethicke, 32, 91-122.

*HARTLEY, L., ANDERSON, J. R., \& PEDERSEN, A. 2018. Process in the community, detain offshore or "turn back the boats"? Predicting Australian asylum-seeker policy support from false beliefs, prejudice, and political ideology. Journal of Refugee Studies.

*HARTLEY, L. K. \& PEDERSEN, A. 2007. Asylum seekers: How attributions and emotion affect Australians' views on mandatory detention of "the other". Australian Journal of Psychology, 59, 119-131.

*HARTLEY, L. K. \& PEDERSEN, A. 2015. Asylum seekers and resettled refugees in Australia: Predicting social policy atitude from prejudice versus emotion. Journal of Social and Political Psychology, 3, 142-160.

*HARTLEY, L. K., PEDERSEN, A. \& DANDY, J. 2012. Attitudes towards asylum seekers: An evaluation of a mature-aged community education programme. Race Equality Teaching, 30, 34-38.

HASLAM, N. 2006. Dehumanization: An integrative review. Personality and Social Psychology Review, 10, 252-264. 
HASLAM, N. \& HOLLAND, E. 2012. Attitudes towards asylum seekers: The Australian experience. In: BRETHERTON, D. \& BALVIN, N. (eds.) Peace Psychology in Australia. New York, NY: Springer US.

*HEALY, E. \& PEDERSEN, A. 2015. Prejudice and Polyculturalism: A Comparison of LGB, TI and Refugee groups. Unpublished manuscript.

HEAVEN, P. C. L. \& CONNORS, J. R. 2001. A note on the value correlates of social dominance orientation and right-wing authoritarianism. Personality and Individual Differences, 31, 925-930.

HODSON, G. \& DHONT, K. 2015. The person-based nature of prejudice: Individual difference predictors of intergroup negativity. European Review of Social Psychology, 26, 1-42.

HUEDO-MEDINA, T., SÁNCHEZ-MECA, J. \& MARÍN-MARTÍNEZ, F. 2006. Assessing heterogeneity in meta-analysis: Q Statistic or I2 Index? Psychological Methods, 193-206.

*KARUNARATNE, K. \& GINGES, J. 2013. Moral distancing: An investigation of domain specific effects with refugees in Australia. University of Melbourne.

*KHERA, M. L. K., HARVEY, A. J. \& CALLAN, M. J. 2014. Beliefs in a just world, subjective well-being and attitudes towards refugees among refugee workers. Social Justice Research, 27, 432-443.

KLOCKER, N. \& DUNN, K. M. 2003. Who's driving the asylum debate: newspaper and government representations of asylum seekers.

*KOC, Y. \& ANDERSON, J. R. 2019. Reducing social distance towards Syrian refugees: The role of acculturation orientation and intergroup anxiety. Journal of Social Issues, Manuscript in Press.

*KOTZUR, P. 2017. Does contact make good neighors? Changes of contact and attitudes towards asylum seekers in the neighbourhood of a recently set up initial reception crises center during the "migration crisis". Manuscript submitted for publication.

LAZARUS, R. S. 1991. Progress on a cognitive-motivational-relational theory of emotion. American Psychologist, 46, 819-834.

LEYENS, J.-P., PALADINO, P. M., RODRIGUEZ-TORRES, R., VAES, J., DEMOULIN, S., RODRIGUEZ- PEREZ, A. \& GAUNT, R. 2000. Leyens, J.-P., Paladino, P. M., Rodriguez-Torres, R., Vaes, J., Demoulin, S., RodriguezPerez, A., et al. (2000). The emotional side of prejudice: The attribution of secondary emotions to ingroups and outgroups. Personality and Social Psychology Review, 4, 186-197. doi:10.1207/S15327957PSPR0402_06. Personality and Social Psychology Review, 4,186-197.

*LOUIS, W. R., DUCK, J. M., TERRY, D. J., SCHULLER, R. A. \& LALONDE, R. N. 2007. Why do citizens want to keep refugees out? Threats, fairness and hostile norms in the treatment of asylum seekers. European Journal of Social Psychology, 37, 53-73.

LOUIS, W. R., ESSES, V. M. \& LALONDE, R. N. 2013. National identification, perceived threat, and dehumanization as antecedents of negative attitudes toward immigrants in Australia and Canada. Journal of Applied Social Psychology, 43, 156-165. 
*LYALL, H. C. \& THORSTEINSSON, E. B. 2007. Attitudes to the Iraq war and mandatory detention of asylum seekers: Associations with authoritarianism, social dominance, and mortality salience. Australian Journal of Psychology, 59, 70-77.

*MANCINI, T. 2017. The role of perception of threats, conservative beliefs and prejudice on prosocial behavioral intention in favor of asylum seekers in a sample of adult laypeople. Manuscript under review.

MCKAY, F. H., THOMAS, S. L. \& KNEEBONE, S. 2012. 'It would be okay if they came through the proper channels': Community perceptions and attitudes toward asylum seekers in Australia. Journal of Refugee Studies, 25, 113-133.

MOHER, D., LIBERATI, A., TETZLAFF, J. \& ALTMAN, D. 2009. Preferred reporting items for systematic reviews and meta-analyses: The PRISMA Statement. 6.

*MORRIS, J. W., \& HEAVEN, P. C. L. 1986. Attitudes and behavioral intentions toward Vietnamese in Australia. The Journal of Social Psychology, 126(4), 513-520. doi:10.1080/00224545.1986.9713619

*NICKERSON, A. M. \& LOUIS, W. R. 2008. Nationality Versus Humanity? Personality, Identity, and Norms in Relation to Attitudes Toward Asylum Seekers. Journal of Applied Social Psychology, 38, 796-817.

OSTRAND, N. 2015. The Syrian refugee crisis: A comparison of response by Germany, Sweden, the United Kingdom, and the United States. Journal of Migration and Human Security, 3, 255-279.

*PALAMOUNTAIN, L. 2009. Attitudes toward asylum seekers: The role of beliefs in procedural fairness. Unpublished manuscript.

*PEDERSEN, A., ATTWELL, J. \& HEVELI, D. 2005. Prediction of negative attitudes toward Australian asylum seekers: False beliefs, nationalism, and self-esteem. Australian Journal of Psychology, 57, 148-160.

*PEDERSEN, A., GRIFFITHS, B. \& WATT, S. E. 2008. Attitudes toward Out-groups and the perception of consensus: All feet do not wear one shoe. Journal of Community \& Applied Social Psychology, 18, 543-557.

*PEDERSEN, A. \& HARTLEY, L. K. 2015. Can we make a difference? Prejudice towards asylum seekers in Australia and the effectiveness of antiprejudice interventions. Journal of Pacific Rim Psychology, 9, 1-14.

*PEDERSEN, A. \& THOMAS, E. F. 2013. 'There but for the grace of God go we': Prejudice toward asylum seekers. Peace and Conflict: Journal of Peace Psychology, 19, 253265.

*PEHRSON, S., BROWN, R. \& ZAGEFKA, H. 2009. When does national identification lead to the rejection of immigrants? Cross-sectional and longitudinal evidence for the role of essentialist in-group definitions. British Journal of Social Psychology, 48, 61-76.

*PERRY, R., PARADIES, Y. \& PEDERSEN, A. 2015. Religious ambivalence: Suppression of pro-social attitudes toward asylum seekers by Right-Wing Authoritarianism. The International Journal for the Psychology of Religion, 25, 1-33. 
PICKERING, S. (2001). Common sense and original deviancy: News discourses and asylum seekers in Australia. Journal of Refugee Studies, 14(2), 169-186. doi:10.1093/jrs/14.2.169

*RIEBLE, C. \& PFUNDMAIR, M. 2016. How contact affects attitudes towards refugees in Germany. Unpublished manuscript.

*SAVIGE, A. \& HAMILTON, D. 2016. Disgusting out-group members': The role of disgust and in-group identification in predicting negative attitudes toward asylum seekers. Australian Catholic University.

*SCHWEITZER, R., PERKOULIDIS, S., KROME, S., LUDLOW, C. \& RYAN, M. 2005. Attitudes towards refugees: The dark side of prejudice in Australia. Australian Journal of Psychology, 57, 170-179.

SIDANIUS, J. \& PRATTO, F. 1999. Social dominance: An intergroup theory of social hierarchy and oppression, New York, NY, Cambridge University Press.

STENNER, K. 2005. The Authoritarian Dynamic, Cambridge, UK, Cambridge University Press.

STEPHAN, W. G. \& FINLAY, K. 1999. The role of empathy in improving intergroup relations. Journal of Social Issues, 55, 729 - 743.

STEPHAN, W. G. \& STEPHAN, C. W. 2000. An integrated threat theory of prejudice. In: OSKAMP, S. (ed.) Reducing prejudice and discrimination. Mahwah, NJ: Lawrence Erlbaum Associates.

*STEWART, K., PEDERSEN, A. \& PARADIES, Y. 2014. It's always good to help when possible, BUT...: Obstacles to bystander anti-prejudice. The International Journal of Diversity in Education, 13, 39-53.

*SUHNAN, A., PEDERSEN, A. \& HARTLEY, L. K. 2012. Re-examining prejudice against asylum seekers in Australia: The role of people smugglers, the perception of threat, and acceptance of false beliefs. The Australian Community Psychologist, 24, 79-97.

TAJFEL , H., \& TURNER , J. C. (1979). An integrative theory of intergroup conflict. In W. G. Austin \& S. Worschel (Eds.), The social psychology of intergroup relations (pp. 33-47). Montery, CA: Brooks/Cole.

TAPIAS, M. P., GLASER, J., KELTNER, D., VASQUEZ, K. \& WICKENS, T. 2007. Emotion and prejudice: Specific emotions toward out-groups. Group Processes \& Intergroup Relations, 10, 27-39.

*TARTAKOVSKY, E. \& WALSH, S. D. 2016. Testing a new theoretical model for attitudes toward immigrants: The case of social workers' attitudes toward asylum seekers in Israel. Journal of Cross-Cultural Psychology, 47, 72-96.

*TEZANOS-PINTO, P. 2010. A normative approach to intergroup contact: The role of ingroup norms regarding interactions with members of the outgroup. Unpublished manuscript.

*TROUNSON, J. S., CRITCHLEY, C. \& PFEIFER, J. E. 2015. Australian attitudes toward asylum seekers: Roles of dehumanization and social dominance theory. Social Behavior and Personality, 43, 1641-1655. 
*TUROY-SMITH, K. M., KANE, R. \& PEDERSEN, A. 2013. The willingness of a society to act on behalf of Indigenous Australians and refugees: the role of contact, intergroup anxiety, prejudice, and support for legislative change. Journal of Applied Social Psychology, 43, E179-E195.

UNITED NATIONS HIGH COMMISSION FOR REFUGEES. 2016. UNHCR viewpoint: 'Refugee' or 'Migrant'- Which is Right? [Online]. Available: http://www.unhcr.org/en-au/news/latest/2016/7/55df0e556/unhcr-viewpointrefugee-migrant-right.html [Accessed].

UNITED NATIONS HIGH COMMISSIONER FOR REFUGEES. 2017. Global Trends: Forced Displacement in 2016 [Online]. Available: www.unhcr.org/5943e8a34.pdf [Accessed].

*VERKUYTEN, M. 2004. Emotional reactions to and support for immigrant policies: Attributed responsibilities to categories of asylum seekers. Social Justice Research, 17, 293-314.

VERKUYTEN, M., MEPHAM, K., \& KROS, M. 2018. Public attitudes towards support for migrants: the importance of perceived voluntary and involuntary migration. Ethnic and Racial Studies, 41(5), 901-918

*VOLLHARDT, J. R., NAIR, R. \& TROPP, L. R. 2016. Inclusive victim consciousness predicts minority group members' support for refugees and immigrants. Journal of Applied Social Psychology, 46, 354-368.

YITMEN, Ş. \& VERKUYTEN, M. 2017. Feelings toward refugees and non-Muslims in Turkey: The roles of national and religious identifications, and multiculturalism. Journal of Applied Social Psychology.

ZDANIUK, A. \& BOBOCEL, D. R. 2011. Independent self-construal and opposition to affirmative action: The role of microjustice and macrojustice preferences. Social Justice Research, 24, 341-364.

*ZÜHLKE-VAN HULZEN, L. 2016. Prejudice and negative behavioural intentions towards refugees: The role of threat and different forms of national identification. Unpublished manuscript. 


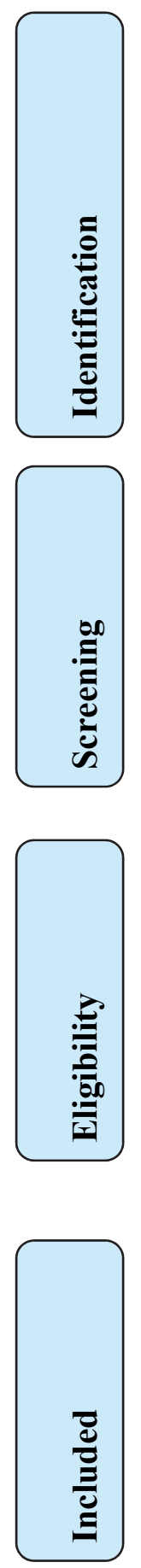

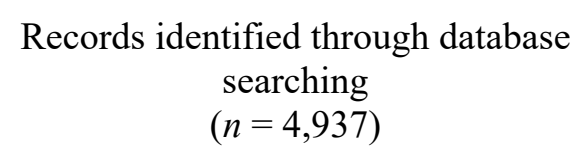

Additional records identified through other sources

$(n=30)$

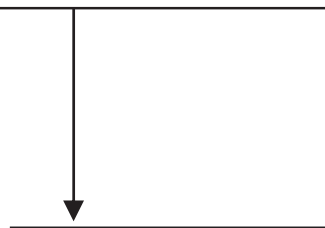

Records excluded $(n=3,375)$

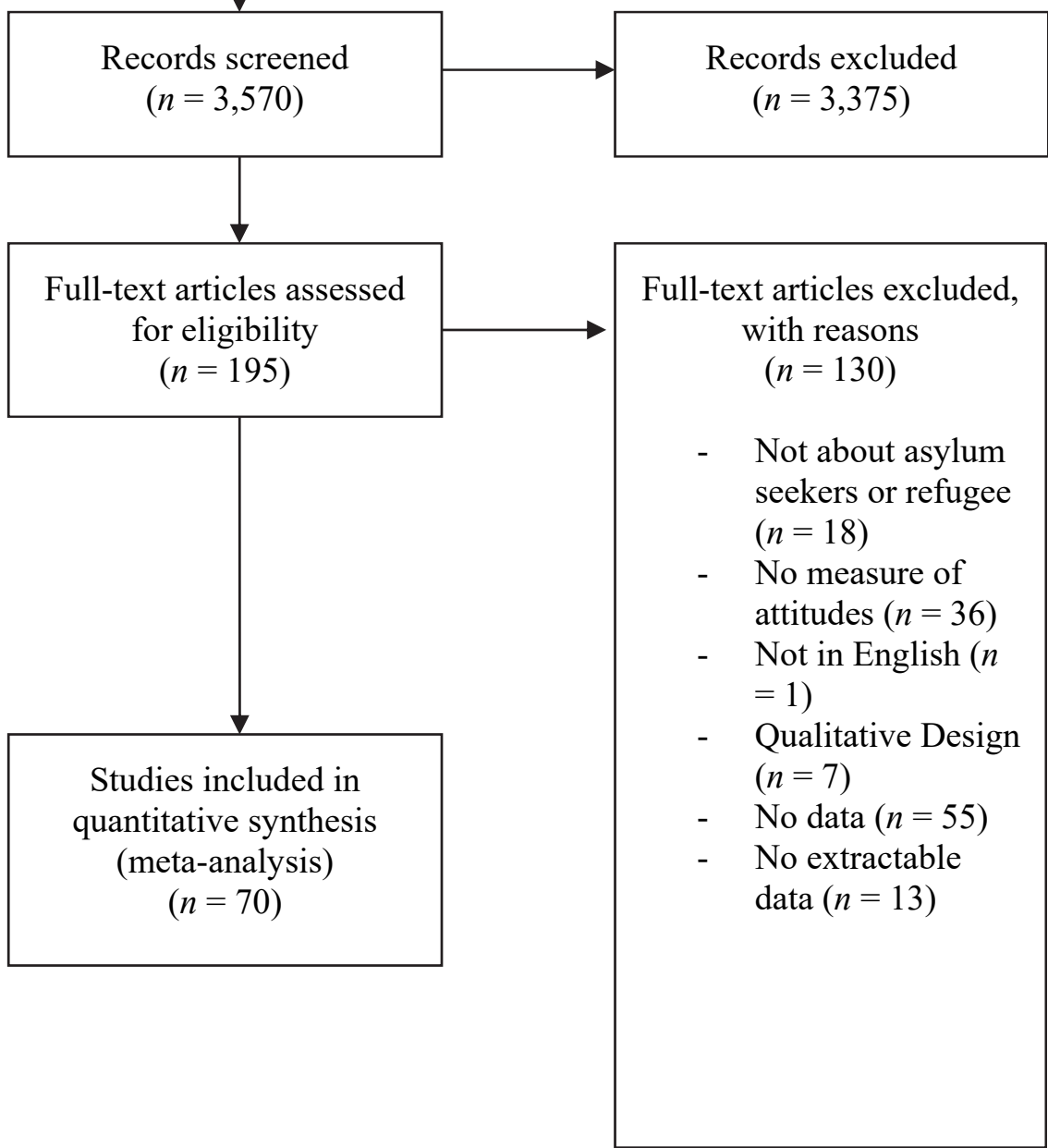

Figure 1. Systematic Database Search and Screening Process. 
Table 1

Total Sample Size (N), Number of Studies (k), Effect Size Estimates (Z and 95\% CI) and Heterogeneity Estimates

\begin{tabular}{lcccccccc}
\hline Factor & $N$ & $k$ & $Z$ & $95 \% \mathrm{CI}$ & $Q_{w}$ & $I^{2}$ & $r$ \\
\hline \multicolumn{1}{c}{ Demographic variables } & & & & & & & & \\
Age & 9,707 & 48 & 0.01 & {$[-0.01,0.11]$} & $899.71^{* *}$ & 95.33 & .01 \\
Gender & 9,786 & 50 & $0.11^{* *}$ & {$[0.09,0.13]$} & 29.93 & 0.00 & .11 \\
Education & 5,825 & 25 & $-0.16^{* *}$ & {$[-0.23,-0.09]$} & $143.25^{* *}$ & 83.94 & -.15 \\
Religious affiliation & 4,818 & 21 & $0.16^{* *}$ & {$[0.06,0.28]$} & $225.79^{* *}$ & 92.47 & .15 \\
Political orientation & 6,479 & 36 & $0.21^{* *}$ & {$[0.14,0.28]$} & $209.11^{* *}$ & 85.65 & .21 \\
National identification & 4,085 & 22 & $0.18^{* *}$ & {$[0.11,0.25]$} & $55.91^{* *}$ & 65.60 & .18 \\
\hline \multicolumn{1}{l}{ Ideological variables } & & & & & & & & \\
Right-wing authoritarianism & 3,950 & 21 & $0.50^{* *}$ & {$[0.38,0.62]$} & $197.69^{* *}$ & 91.40 & .46 \\
Social dominance orientation & 4,004 & 18 & $0.50^{* *}$ & {$[0.27,0.72]$} & $737.82^{* *}$ & 97.83 & .46 \\
Macro justice principles & 343 & 4 & $-0.29^{* *}$ & {$[-0.57,-0.02]$} & $17.92^{* *}$ & 83.26 & .30 \\
Micro justice principles & 330 & 4 & 0.00 & {$[-0.31,0.32]$} & $21.83^{* *}$ & 86.26 & .00 \\
\hline
\end{tabular}

Threat Perception variables

Symbolic Threat

$\begin{array}{lllllll}636 & 3 & 0.98^{* *} & {[0.77,1.18]} & 13.78^{* *} & 85.48 & .76\end{array}$

Realistic Threat

$\begin{array}{lllllll}636 & 3 & 1.11^{* *} & {[0.61,1.61]} & 80.81^{* *} & 97.53 & .82\end{array}$

Emotion variables

Empathy

$\begin{array}{llllll}599 & 4 & -0.32 & {[-0.93,0.29]} & 152.30 * * & 98.08\end{array}$

Notes: ${ }^{*} p<.05,{ }^{*} p<.001 ; \mathrm{CI}=$ confidence interval. 


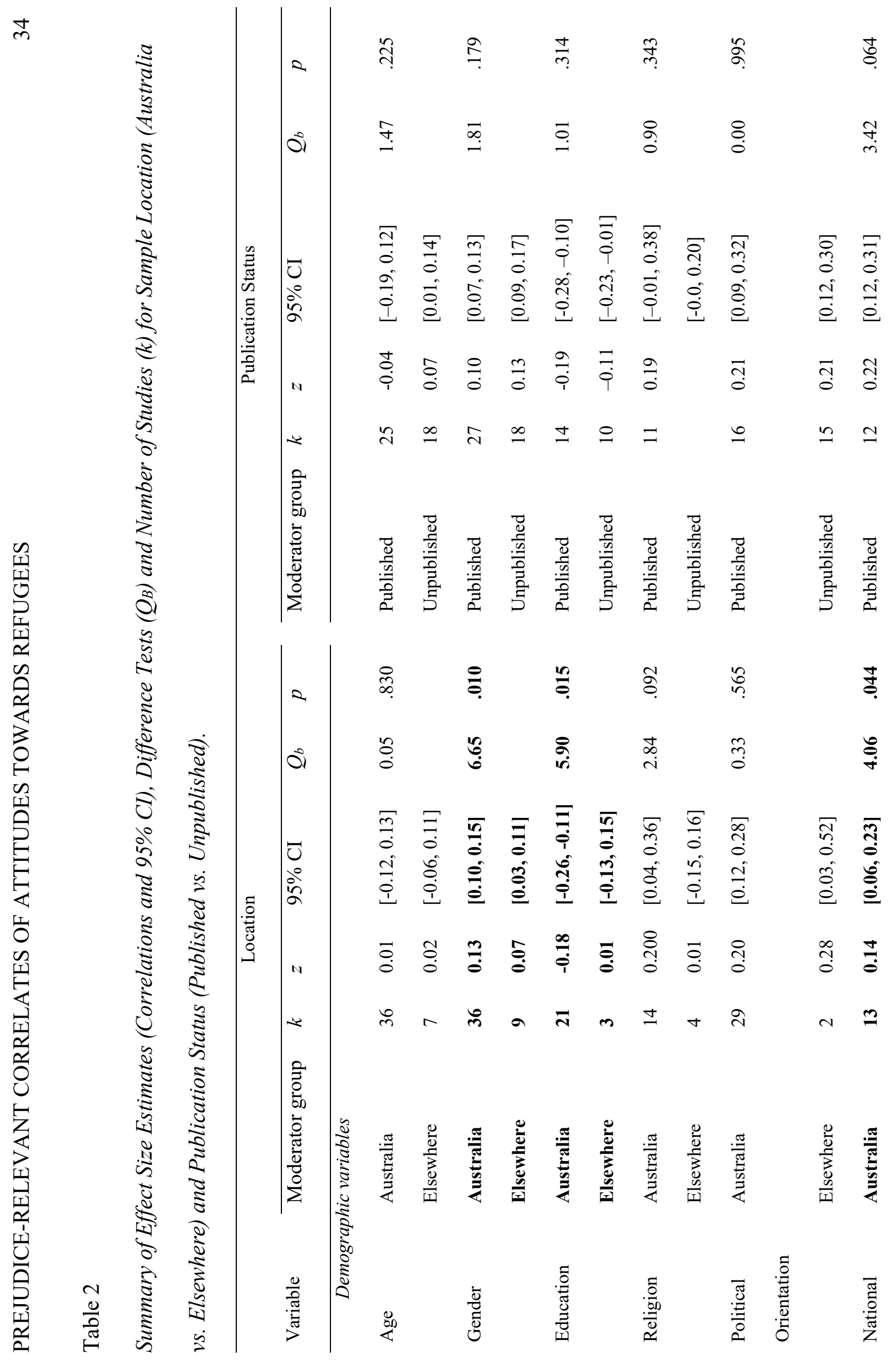




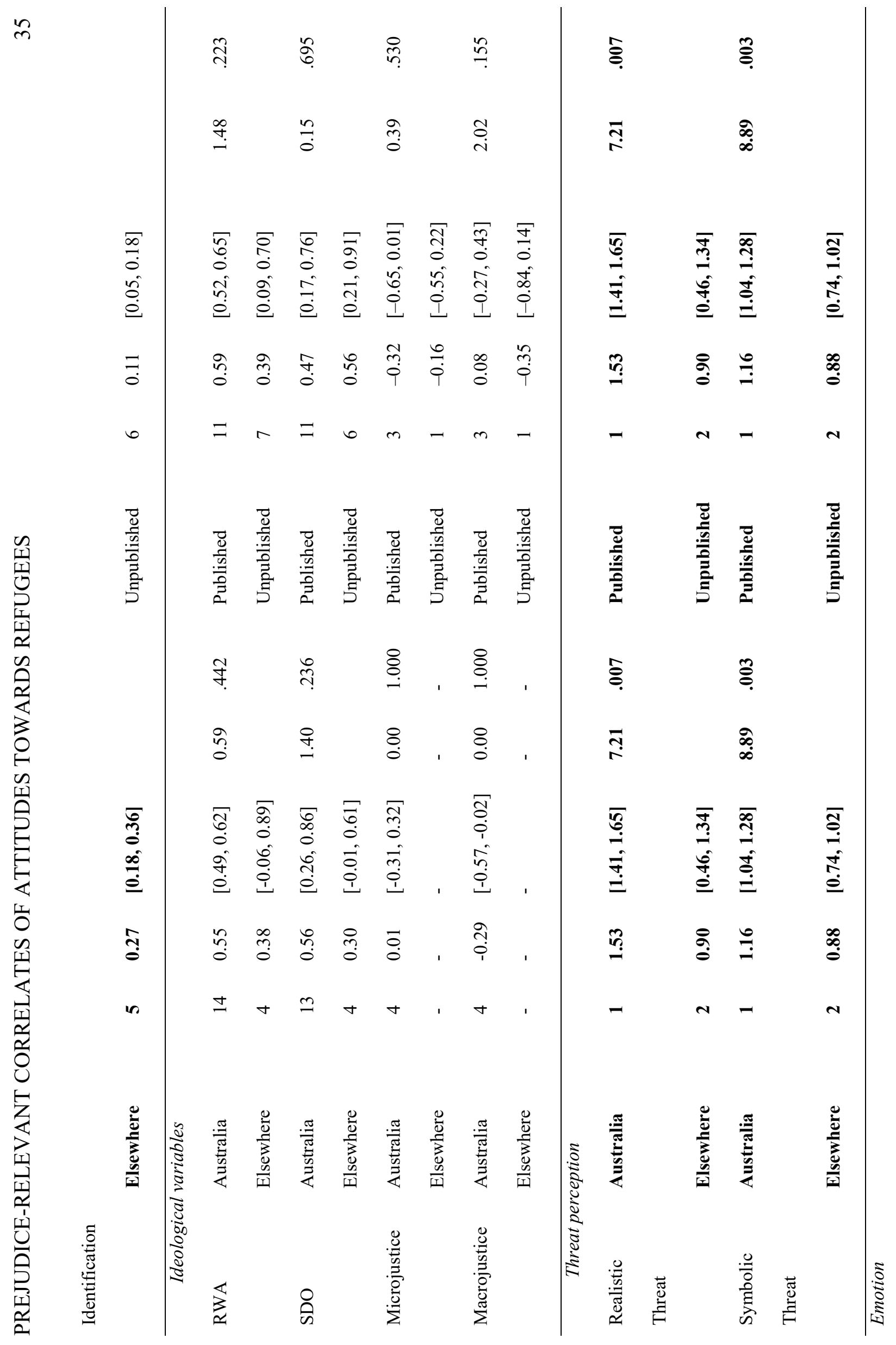




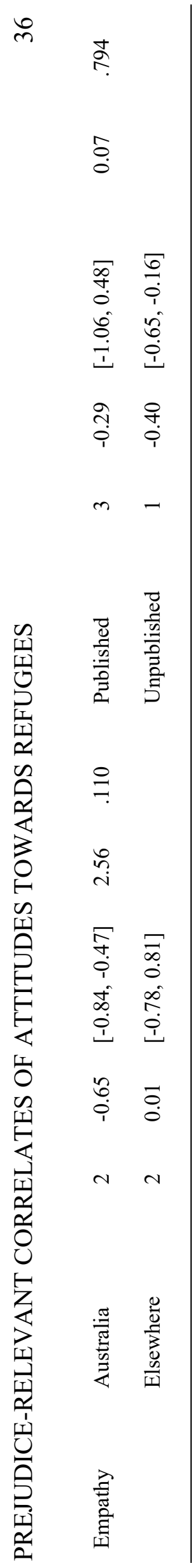

